\title{
Experimental evidence on the effect of incentives and domain in risk aversion and discounting tasks
}

\author{
Emmanouil Mentzakis ${ }^{1} \cdot$ Jana Sadeh $^{1}$
}

Accepted: 2 July 2021 / Published online: 5 August 2021

(C) The Author(s) 2021

\begin{abstract}
Environmental policy evaluation is often criticised for employing discount rates that have little grounding in research. Yet, experimental research aimed at eliciting realistic rates will inevitably require strong assumptions of external validity, while also placing large cognitive demands on subjects by processing tasks of increased unfamiliarity. We use a controlled lab experiment to test the impact of incentives on risk aversion and discounting tasks for monetary and environmental goods. We find that, on average, incentives have little effect on risk aversion or discounting tasks in either domain. Exploring heterogeneity by treatment and socio-demographics some significant patterns emerge. Further, contrary to past work, we find evidence of domain (monetary $v s$. environmental good) effects in both risk and discounting.
\end{abstract}

Keywords Time preferences · Risk aversion · Hypothetical bias ·

Experimental incentives · Domain effects

JEL Classification C51 · C91 · D81 - Q50

\section{Introduction}

Choices over uncertain outcomes that play out over time permeate most individual and societal decisions. Investments in education, health or environment require quantifying preferences over temporal trade-offs and risky choices. Time preference expresses the relative weight given to tomorrow as opposed to today, with individuals commonly choosing benefits that accrue sooner rather than later and

Jana Sadeh

Jana.Sadeh@soton.ac.uk

Emmanouil Mentzakis

E.Mentzakis@ soton.ac.uk

1 Department of Economics, University of Southampton, SO17 1BJ, Southampton, UK 
therefore discounting future outcomes. With future outcomes embedding an element of uncertainty they are further penalised as individuals recognize their probabilistic nature.

These characteristics, impatience and risk aversion, are mirrored in environmental and health policy appraisals where discount rates, encompassing time preference and risk aversion, are applied to benefits occurring in the future. When balanced out with costs (almost always incurring at the present), future benefits must be magnitudes greater to achieve a net-benefit. In practice, discount rates raise the threshold for projects to be considered welfare-increasing and as such, can make or break policy initiatives. Yet, there is very little empirical evidence that can guide the adoption of discount rates in public policy. One main reason for this is the inability of policy makers to measure time preference behaviour where no functioning markets exist. A second best solution would be the use of experimental hypothetical scenarios where contexts and good specific rates are elicited and subsequently employed in policy evaluation. However, the implicit assumption of external validity for these hypothetical scenarios is a crucial step in moving towards a more evidenced based decision making framework.

This paper focuses on the salient incentivization of subjects participating in economic experiments, which has long been considered a fundamental principle that allows for the elicitation of the true nature of participants' preferences, behaviour and choices. Lack of salient incentives is commonly considered to not sufficiently motivate participants to correctly process the task at hand or, at the extreme, to willingly misrepresent their preferences. Understanding the impact of these incentives on risk aversion and discounting choices made by subjects evaluating environmental outcomes is a crucial building block to the wider application of these hypothetical studies. However, the impact of experimenter choices on payment mechanisms is a central question that has not received enough attention in the literature (Cox et al., 2015).

Previous work on payoff effects on risk choices has found that in situations involving complex gambles, payoffs have a significant effect on subjects' choices, indicating that more cognitively demanding tasks, or tasks with high stakes, are influenced by incentives (Holt \& Laury, 2002). Literature on hypothetical bias in environmental and health valuation studies suggests that the lack of familiarity with the good being evaluated leads to differences in choices when faced with incentivised outcomes (List \& Gallet, 2001). In addition, the effect of incentives has been found to be more crucial in situations that involve a temporal dimension where the subject is required to visualise future scenarios, which makes the current investigation of the effect of payoffs on inter-temporal choice even more pertinent (Beattie \& Loomes, 1997).

Building on past literature, this paper tests the effect of incentives on elicited risk aversion and discounting parameters for two domains, namely, money and environment. It is the first experiment to do so for an environmental good, while the monetary good allows benchmarking to previous studies. Our contributions are threefold. First, we contribute to the overall debate on experimental design and the importance of incentives in risk aversion and time preference experiments and attempt to extract a common message on the possible impact of incentives. Second, we present 
evidence for environmental economics, and possibly other non-monetary domains, on the reliability and validity of implementing experimental methodology for elicitation of risk and time preferences (primarily developed for use with monetary incentives) in hypothetical contexts. To the best of our knowledge this is the first study to do so. Third, joint estimation of risk and discount parameters in structural models, offers new insights into the impact of econometric methodology on past evidence on the lack of domain effects.

We find that, on average, incentives have little effect on risk aversion or discounting tasks in either domain. Exploring heterogeneity by treatment and sociodemographics, pro-environmental attitudes influence the direction of the incentive effect on risk aversion for subjects. Incentives lower environmental discount rates for those with high cognitive reflection abilities, while they increase discount rates in monetary treatments when controlling for subject's expenditure levels. Contrary to past work, we find evidence of domain (monetary vs. environmental good) effects in both risk and discounting, with subjects exhibiting higher risk aversion and higher discount rates in the environmental domain. The remainder of the paper proceeds as follows. Section 2 briefly presents past literature on the effect of incentivization on risk, discounting and non-strategic games. The experimental design, instrument and analysis is described in Section 3 with results being presented in Section 4. Section 5 discusses our findings and concludes.

\section{Background}

The effect of experimental incentives has often been the subject of discussion in the literature in various contexts, including performance, value elicitation, as well as risk aversion and discounting (Smith \& Walker, 1993; Read, 2005). We review past work in an attempt to bring together findings from the experimental literature on payoff effects as well as findings from the environmental economics literature on hypothetical bias given the crossover in the relevance of these two strands of literature.

\subsection{Payoff effect in risk aversion}

A large body of literature is dedicated to understanding the impact of monetary incentives on risk tasks in laboratory experiments. Since risk aversion tasks measure preferences rather than performance, there is no way of assessing whether incentives improve performance other than to monitor differences between the two treatments or any deviation from a priori expectations of economic theory. Findings from such studies are mixed. Beattie and Loomes (1997) find no effect of incentives on risk aversion, while Grether and Plott (1979) and Edwards (1953) find evidence of more risk-seeking behavior in incentivised gambles. Battalio et al. (1990), Binswanger (1980), Hogarth and Einhorn (1990), and Holt and Laury (2002) find the opposite effect, i.e. subjects are more risk averse when presented with an incentivized choice of gambles and Cubitt et al. (1998) only find evidence of increased risk aversion for complex multi-stage gambles. A review of 74 experiments comparing different levels 
of financial incentives also found no effect of financial incentives on mean performance but did note a reduction in variance and a reduction in presentation effects (Camerer \& Hogarth, 1999).

Comparing different payoff structures (hypothetical vs. random-lottery payment vs fully paid experiment) ${ }^{1}$ Beattie and Loomes (1997) found no evidence of an incentive effect in three of the four gambles they presented to subjects, something also noted by Davis and Holt (1993). The one gamble which exhibited significant differences had the unique characteristic of being a multi-stage gamble requiring increased cognitive effort on the part of subjects to internalise future scenarios, suggesting that the impact of incentives is task-specific. Camerer (1995) argued that effects of payments are task specific, with incentives in decisions under risk and uncertainty not improving subjects behavior (i.e. bringing them closer to a priori expectations based on axioms of rationality), while Cubitt et al. (1998) similarly concluded that the effect of payoffs is not significant for simple tasks but may become more relevant for more complex ones.

\subsection{Effect of incentives in discounting}

The presence of a payoff effect in discounting experiments is less populated. Kirby and Maraković (1995) suggest that discount rates elicited for real monetary payoffs are higher than those for hypothetical outcomes. These findings are initially mirrored in the findings of Coller and Williams (1999) but the conclusions are less clear once data issues are accounted for. There is no literature on payoff effects in environmental discounting, this will be the first experiment to test for them.

When looking at environmental discounting, the complexity involved in incentivizing environmental outcomes has meant that with few exceptions experimental studies have been hypothetical in nature (Ioannou \& Sadeh, 2016; Hardisty \& Weber, 2009; Meyer, 2013). The work by Viscusi et al. (2008) has demonstrated that discount rates can also be estimated in the context of stated preference environmental valuation with the simple addition of time delay as a dimension. Nevertheless, the hardest element to implement in both experimental and stated preference studies is incentivization. Environmental outcomes cannot be abstracted to a monetary equivalent without losing the salience of the good itself and if the good is presented as an environmental outcome the payment of participants becomes problematic. This has resulted in most experiments adopting a hypothetical approach and as such there have been no comparisons of discount rates under incentivised and hypothetical environmental scenarios.

\subsection{Effect of incentives in stated preferences valuations}

Given the absence of work on the effect of incentives in environmental discounting, we look towards the literature on stated preference studies for valuing environmental

\footnotetext{
${ }^{1}$ Random-lottery payment implies contexts where subjects perform multiple risk tasks with only one of them being randomly selected to be paid out, whereas fully paid experiments ask subjects to make one or multiple gamble choices and all outcomes are paid out in real money.
} 
goods. While valuation is not the objective in this experiment, discounting tasks are essentially asking respondents to value an environmental good at two different points in time and then express their preference for either. In this context, findings from the valuation literature may help inform a priori expectations.

A large environmental and health literature has raised concerns over hypothetical bias $^{2}$ in willingness-to-pay (WTP) tasks. While there are cases where hypothetical and incentivized valuations have appeared identical (Smith \& Mansfield, 1998; Johannesson, 1997) most studies find that hypothetical valuations exceed actual values (List \& Shogren, 1998; Fox et al., 1998; Cummings et al., 1995). A meta analysis of 29 experimental studies found that hypothetical valuations were larger than actual ones by a factor of 3 (List \& Gallet, 2001), while a later meta-analysis of 28 stated preference valuation studies found differences by a factor of 2.60 (Murphy et al., 2005).

Looking at the determinants of hypothetical bias, List and Gallet (2001) highlight familiarity of subjects with the question being posed as the main driver of differences between hypothetical and incentivized valuations - which are perceived as errors made by subjects in conveying their true value. The issue of familiarity and certainty in ones responses is implicit in Johannesson (1997) who observes that eliciting subjects' confidence in their valuation and controlling for it mitigates the presence of hypothetical bias in the valuation exercise. Familiarity is also cited by Harrison and Rutström (2008) as the possible reason behind Smith and Mansfield (1998)'s lack of evidence of hypothetical bias.

\section{Methodology}

Risk and time preferences were elicited for money and an environmental good in a controlled lab experiment. The experiment was conducted over eight sessions, half with incentivized and half with hypothetical tasks. With the exception of the payoffs for the incentivized tasks the incentivized and hypothetical treatments were identical in all other ways (including both having a show up fee). Participants were randomized to a treatment (i.e. incentivised or hypothetical) and a good (i.e. money or environment) in a between-subjects design. Four experimental groups emerge from this setup. Group A completed the incentivized tasks with money, Group B the incentivized tasks with environment, Group $\mathrm{C}$ the hypothetical tasks with money and Group D the hypothetical tasks with environment. Once allocated to a group, a subject sequentially undertook a discounting and a risk aversion task. At the end of the experiment individual information on subjects cognitive reflection abilities, environmental attitudes and demographics was collected. ${ }^{3}$

The choice of environmental good required it to be divisible so as to enable the incremental increase in the magnitude of the outcome for the risk and discounting

\footnotetext{
${ }^{2}$ Hypothetical bias is termed as the discrepancy between stated/hypothetical and actual/incentivized WTP values, whether in between or within subject comparisons.

${ }^{3}$ Experimental instructions are available at https://jana.sadeh.co.uk/wp-content/uploads/2017/08/ Appendix.pdf.
} 
task. In addition, it had to be one that was familiar to subjects and credible. Following Ioannou and Sadeh (2016), the good chosen was a locally-based project that distributed outdoor bee-friendly plants to staff and students at a UK university. Subjects were informed of the project in the experiment and told that different bee-friendly plants would be chosen depending on the season they are distributed to ensure that they are immediately beneficial. ${ }^{4}$ The environmental project was described in a succinct and neutral manner.

The experimental sessions were conducted in the university's Social Sciences Experimental Lab and subjects were recruited from the university's student population using an electronic recruitment system. Subjects were allowed to participate in only one session. Each session had at most 16 subjects (the maximum lab capacity) and lasted approximately 45 minutes. The experiment was programmed and conducted using the z-Tree software (Fischbacher, 2007).

All subjects were given a $£ 5$ show up fee in cash following the completion of the experiment. In the incentivised treatment subjects were also given the opportunity to receive an additional payment. They were paid using a random-lottery payment mechanism for the monetary and environmental discounting and risk aversion tasks (Coller \& Williams, 1999; Harrison et al., 2002). In addition a second layer of randomness was applied, where only one subject is paid for the risk aversion tasks and one subject is paid for the discounting tasks (i.e. a double layered random payment mechanism). Paying subjects for one of the decisions they make has been shown to be incentive compatible as long as the different choices (Brown \& Healy, 2018; Cox et al., 2015). In addition, choosing one participant to receive the payment has also been shown to be incentive compatible (Charness et al., 2016). There was no payment for the remaining tasks. The subjects of the hypothetical treatment were only paid their participation fee. Each of the sequential tasks administered are described in the paragraphs below.

\subsection{Discounting}

The Monetary Discounting and the Environmental Discounting tasks present subjects with repeated choices between a smaller sooner and a larger later outcome. The smaller sooner amount is kept fixed, whereas the larger later amount progressively increases in order to elicit the point at which subjects become indifferent between the two outcomes. This fixed sequence titration method is a popular elicitation method for intertemporal preferences (Andersen et al., 2008; Harrison \& Lau, 2005; Hardisty $\&$ Weber, 2009) and has been found to be the simplest method out of those that best predict real world outcomes (Hardisty et al., 2013).

\footnotetext{
${ }^{4}$ The magnitude of the choices in the monetary domain and the environmental domain were calibrated using two contingent valuation studies carried out at the university prior to the experiment. The mean willingness to pay for a plant was at $£ 4$.98. Consequently, a conversion rate of 1 plant $=£ 5$ was implemented. Subjects were therefore presented with choices starting at $£ 50$ in the monetary domain and 10 plants in the environmental domain.
} 
Subjects were presented with six progressively larger trade-offs for three different delay periods: (i) a 3-month delay period, (ii) a 6-month delay period, and (iii) a 12month delay period. Thus, in total subjects had to respond to $6 \times 3=18$ binary questions for each of the monetary and the environmental domains (see Table 1 for exact amounts).

\subsection{Risk aversion}

Risk preferences were captured through a variant of the Eckel-Grossman test (Eckel \& Grossman, 2002), where subjects are presented with five gambles of varying riskiness and are required to select the one they prefer. All gambles have two possible eqi-probable outcomes, i.e. Outcome $\mathrm{X}$ with $50 \%$ likelihood and Outcome $\mathrm{Y}$ with $50 \%$ likelihood. In addition, the expected payoffs are easy to calculate and the increasing variance as the gambles get riskier is large enough to be noticeable.

Both the Monetary Risk Aversion Test and the Environmental Risk Aversion Test were calibrated at a magnitude level that is comparable to the choices given to subjects in the discounting tasks. The gambles offered started with a sure win, with an option with identical outcomes (a gain of $£ 50 / 10$ plants) and moved to options of increasing variance at the point where the last option's equiprobable outcomes were $£ 5$ and $£ 162.50$ (or 1 plant and 33 plants). The conversion rate of money per plant used was $£ 5$ (see Table 2 for the gambles presented).

\subsection{Other tasks}

In addition to the core discounting and risk aversion tasks the experiment collected information on relevant individual characteristics to allow testing for heterogeneity of effects in the analysis.

Subjects were presented with the Cognitive Reflection Test (CRT), is a measure of the individual's ability to suppress a spontaneous response in favor of a more

Table 1 Discounting tasks

\begin{tabular}{lllll}
\hline Monetary discounting & & & Environmental discounting & \\
\cline { 5 - 5 } $\begin{array}{llll}\text { Smaller sooner } \\
(£)\end{array}$ & $\begin{array}{l}\text { Larger later } \\
(£)\end{array}$ & & $\begin{array}{l}\text { Smaller sooner } \\
\text { (plants) }\end{array}$ & $\begin{array}{l}\text { Larger later } \\
\text { (plants) }\end{array}$ \\
\hline 50 & 55 & 10 & 11 \\
50 & 60 & 10 & 12 \\
50 & 65 & 10 & 13 \\
50 & 70 & 10 & 14 \\
50 & 75 & 10 & 15 \\
50 & 100 & 10 & 20 \\
\hline
\end{tabular}

The binary options presented to participants of the monetary discounting task are displayed in the first two columns. Values are given in GBP. The binary options presented to participants of the environmental discounting task are displayed in the latter two columns. These are denominated in plants 
Table 2 Risk aversion tasks

\begin{tabular}{|c|c|c|c|c|}
\hline \multicolumn{5}{|c|}{ Monetary Risk Aversion Test } \\
\hline \multirow[t]{3}{*}{ Option } & \multicolumn{2}{|c|}{ Outcome X } & \multicolumn{2}{|c|}{ Outcome Y } \\
\hline & Payoffs & Probability & Payoffs & Probability \\
\hline & $(£)$ & $(\%)$ & $(£)$ & $(\%)$ \\
\hline 1 & 50.00 & $50 \%$ & 50.00 & $50 \%$ \\
\hline 2 & 35.00 & $50 \%$ & 87.50 & $50 \%$ \\
\hline 3 & 25.00 & $50 \%$ & 112.50 & $50 \%$ \\
\hline 4 & 15.00 & $50 \%$ & 137.50 & $50 \%$ \\
\hline 5 & 5.00 & $50 \%$ & 162.50 & $50 \%$ \\
\hline \multicolumn{5}{|l|}{ Panel B } \\
\hline & \multicolumn{4}{|c|}{ Environmental Risk Aversion Test } \\
\hline \multirow[t]{3}{*}{ Option } & \multicolumn{2}{|c|}{ Outcome X } & \multicolumn{2}{|c|}{ Outcome Y } \\
\hline & Payoffs & Probability & Payoffs & Probability \\
\hline & (plants) & $(\%)$ & (plants) & $(\%)$ \\
\hline 1 & 10 plants & $50 \%$ & 10 plants & $50 \%$ \\
\hline 2 & 7 plants & $50 \%$ & 18 plants & $50 \%$ \\
\hline 3 & 5 plants & $50 \%$ & 23 plants & $50 \%$ \\
\hline 4 & 3 plants & $50 \%$ & 28 plants & $50 \%$ \\
\hline 5 & 1 plant & $50 \%$ & 33 plants & $50 \%$ \\
\hline
\end{tabular}

Panel A displays the options presented to participants of the monetary risk aversion task. Participants were presented with the five gambles presented here and were required to select their preferred gamble. Panel B displays the options presented to participants of the environmental risk aversion task. Participants were presented with the five gambles presented here and were required to select their preferred gamble. The magnitude of the gambles is calibrated to be of equivalent value, with the rounding up of payoffs occuring in the environment domain

deliberately-thought out one (i.e. subjects' reflective ability) (Frederick, 2005). The questions themselves require no special linguistic or mathematical skills.

An environmental questionnaire was administered in the penultimate stage in order to avoid any unintentional impact they might have on subjects' choices. Subjects are asked to express their level of agreement with 17 statements on a range of environmental issues and through their responses are classified into seven groups following Defra (2008). Following this, a valuation question ${ }^{5}$ for a plant was included to elicit subjects' willingness-to-pay for the environmental good.

Finally, information on subjects' age, sex, monthly expenditure on nonaccommodation expenses and ownership status of parents' home was collected.

\footnotetext{
${ }^{5}$ Payment card format with 6 interval bids: $£ 0, £ 0.5, £ 2.5, £ 5, £ 10, £ 15, £ 15+$
} 


\subsection{Statistical analysis}

The effect of incentives and domain on risk aversion and discounting choices is initially tested on the raw responses using $\chi^{2}$ and Kolmogorov-Smirnov (KS) tests. Subsequently, risk and discounting parameters are jointly estimated in structural models (Andersen et al., 2008; 2014; Andreoni \& Sprenger, 2012). Joint estimation avoids imposing risk neutrality in the time preferences' utility function, a common assumption when analysing time preference data on their own, and allows for the correct curvature of the utility function as both risk aversion and discount parameters are elicited for the same subject and modelled simultaneously.

Starting with the contribution of risk aversion task to the overall likelihood, a constant relative risk aversion (CRRA) parametric utility function is assumed

$$
U(M)=(\omega+M)^{(1-r)} /(1-r)
$$

where $r$ is the CRRA coefficient as implied by the bounds of the Eckel-Grossman test presented in Section 3.2, ${ }^{6} \omega$ is background consumption (i.e. also thought of as endowment or wealth) and $M$ is the pay-off from the experiment. For probability $p\left(M_{j}\right)$ for each outcome $M_{j}$ (as induced by the experimenter), the expected utility for lottery $i$ can be written as

$$
E U_{i}=\sum\left(p\left(M_{j}\right) \times U\left(\omega+M_{j} / \eta\right)\right)
$$

where $\eta$ represents the periods of time over which the pay-off will be integrated into existing wealth $\omega$, which for simplicity we assume $\eta=1$, implying that consumption of pay-off happens in one period (Andersen et al., 2008). Using the parametric utility function in Eq. 1 and the pair-wise nature of the experiment, the log-likelihood of Outcome $\mathrm{Y}$ with $E U_{Y}$ over Outcome $\mathrm{X}$ with $E U_{X}$ is given by

$$
\ln L^{R A}(r, \mu ; y, \omega)=\sum\left(\left(\ln (\nabla E U) \mid y_{i}=1\right)+\left(\ln (1-\nabla E U) \mid y_{i}=-1\right)\right)
$$

where $\nabla E U=E U_{Y}^{1 / \mu} /\left(E U_{X}^{1 / \mu}+E U_{Y}^{1 / \mu}\right)$ with $\mu$ a structural error parameter to allow for randomness in choices (Holt \& Laury, 2002) and $y=1$ denoting Outcome $\mathrm{X}$, while $y=-1$ Outcome $\mathrm{Y}^{7}$ In estimations we set $\omega=£ 7.5$ for the monetary task, which is the average daily consumption subjects stated in the post-experimental survey. For the environmental task we set $\omega=£ 0.4$ which is equal to the daily average expenditure on "plants, flowers, seeds, fertiliser and insecticides" according to the Office for National Statistics (ONS, 2015).

While the utility function for risk aversion has the risk task pay-off received immediately following the experiment, the utility function for the discounting task recognises that the front-end delay implies a possible time lag in the integration of the payoff with wealth. In a series of pair-wise choices, subjects compare a Smaller sooner $\left(M_{A}\right)$ and a Larger later $\left(M_{B}\right)$ gamble and select the one with the

\footnotetext{
${ }^{6}$ Note that $r=0$ denotes risk neutrality, $r>0$ risk aversion and $r<0$ risk-loving behaviour.

${ }^{7}$ Note that our experiment did not allow statements of indifference.
} 
higher present value. The discounted utility for options A and B are, respectively, given by

$$
\begin{aligned}
& P V_{A}=\sum\left(\left(1 /(1+\delta)^{(i-t)}\right) U\left(\omega+M_{A} / \lambda\right)\right)+\sum\left(\left(1 /(1+\delta)^{(i-t)}\right) U(\omega)\right) \\
& P V_{B}=\sum\left(\left(1 /(1+\delta)^{(i-t)}\right) U(\omega)\right)+\sum\left(\left(1 /(1+\delta)^{(i-t)}\right) U\left(\omega+M_{B} / \lambda\right)\right)
\end{aligned}
$$

where $\delta$ is the discount rate and $\lambda$ is the number of periods over which the outcome is integrated with background consumption (i.e. the number of days over which subjects expect to spend the earnings of the discount rate task). Following a common assumption in the discounting literature, we set $\lambda=1$, implying that subjects do not smooth consumption over time with consumption of earnings from the experiment happening over one day (Frederick et al., 2002). ${ }^{8} 9$ Substituting the utility function from Eq. 1, the parametric versions of Eqs. 4 and 5 become

$$
\begin{aligned}
P V_{A}= & \sum_{i=t, \ldots, t+\lambda-1}\left(\left(1 /(1+\delta)^{(i-t)}\right)\left(\omega+M_{A} / \lambda\right)^{1-r}\right) \\
& +\sum_{i=t+\tau, \ldots, t+\tau+\lambda-1}\left(\left(1 /(1+\delta)^{(i-t)}\right) \omega^{(1-r)}\right) \\
P V_{B}= & \sum_{i=t, \ldots, t+\lambda-1}\left(\left(1 /(1+\delta)^{(i-t)}\right) \omega^{1-r}\right) \\
& +\sum_{i=t+\tau, \ldots, t+\tau+\lambda-1}\left(\left(1 /(1+\delta)^{(i-t)}\right)\left(\omega+M_{B} / \lambda\right)^{(1-r)}\right)
\end{aligned}
$$

For the exponential discount function, Eq. $1,{ }^{10}$ the log-likelihood for discounting is

$$
\ln L^{D R}(r, \delta, \mu, \nu ; y, \omega, \lambda, \mathbf{X})=\sum\left(\left(\ln (\nabla P V) \mid y_{i}=1\right)+\left(\ln (1-\nabla P V) \mid y_{i}=-1\right)\right)
$$

where $\nabla P V=P V_{B}^{1 / v} /\left(P V_{A}^{1 / v}+P V_{B}^{1 / v}\right)$ with $v$ a structural error parameter to allow for randomness in choices (Holt \& Laury, 2002) and $y=1$ and $y=-1$ denoting the smaller sooner and larger later outcomes, respectively. ${ }^{11}$ Setting $r=0$ estimates discount rates under risk-neutrality.

The joint log-likelihood is obtained as the summation of the risk and discounting log-likelihoods

$$
\ln L(r, \delta, \mu, v ; y, \omega, \lambda)=\ln L^{R A}+\ln L^{D R}
$$

\footnotetext{
${ }^{8}$ For cases where $\lambda>\eta$ this specification embodies the dual-self model where short term temptation battles with long term planning (Fudenberg \& Levine, 2006).

${ }^{9}$ Andersen et al. (2008) further consider alternative specifications of $\lambda>1$ which allows for integration with background daily consumption over periods longer than a day. They find that $\delta$ is sensitive to the value of $\lambda$ with $\delta$ rising as $\lambda$ rises reaching a maximum discount rate (for cases of risk neutrality, $r=0$ ) as $\lambda$ goes to infinity.

${ }^{10} \mathrm{~A}$ hyperbolic specification is also estimated to check sensitivity of results.

${ }^{11}$ Responses that reflect indifference are not allowed in the experiment.
} 
Given our interest in the impact of incentives and domain on the estimates of $r$ and $\delta$, heterogeneity can be examined by making both of these parameters linear functions of treatment variables. The risk aversion parameter (the corresponding specification is also used for $\delta$ but omitted for brevity) then becomes

$$
\widehat{r}=\widehat{r_{0}}+\widehat{r_{E n v}} \times E n v+\widehat{r_{\text {Real }}} \times \text { Real }+\widehat{r_{\text {EnvReal }}} \times E n v \times \text { Real }
$$

where Real is a dummy variable taking the value of 1 for observations from the incentivised treatments (and zero otherwise), Env is a dummy taking the value of 1 for subjects who face environmental tasks (and zero otherwise), Env $\times$ Real is their interaction. We extend this specification to explore heterogeneity according to observable individual characteristics, $X$, by introducing further interaction terms in the above linear function

$$
\begin{aligned}
\widehat{r}= & \widehat{r_{0}}+\widehat{r_{X}} \times \mathbf{X}+\widehat{r_{E n v}} \times E n v+\widehat{r_{E n v X}} \times E n v \times \mathbf{X} \\
& +\widehat{r_{\text {Real }}} \times \text { Real }+\widehat{r_{\text {RealX }}} \times \text { Real } \times \mathbf{X}+\widehat{r_{\text {EnvReal }}} \times E n v \times \text { Real } \\
& +\widehat{r_{\text {EnvReal }}} \times \text { Env } \times \text { Real } \times \mathbf{X}
\end{aligned}
$$

where $\mathbf{X}$ denotes individual characteristics and includes Sex (equal to 1 for females; 0 otherwise), HighCRT (equal to 1 for those scoring high on the CRT test; ${ }^{12} 0$ otherwise), HighExp (equal to 1 for those with above median monthly expenditure on non-accommodation expenses; 0 otherwise) and Green (equal to 1 for those with positive -"green"- environmental attitudes; ${ }^{13} 0$ otherwise). Given the three-way interactions needed to identify effects, these extended specifications occasionally lead to convergence issues. The large demands placed on the data through the highly non-linear structural model, the relatively small sample size and/or the actual absence of significant heterogeneity are all possible explanations. To resolve convergence issues, we explore heterogeneity one characteristic at a time, while we set to zero any parameters shown to lack identification in our data.

\section{Results}

A total of 120 subjects participated over eight experimental sessions, 58 subjects saw the incentivised version and 62 subjects saw the hypothetical version of the experiment. Table 3 presents a comparison of the socio-demographic characteristics among the four groups. Overall, small variations are observed across groups with $\chi^{2}$ tests (for categorical variables) and $t$-tests (for continuous variables) suggesting no statistically significant differences.

\subsection{Responses to RA and DR questions}

Table 4 presents the raw responses to the risk aversion task. Moving from the hypothetical to the incentivized treatment there is an increase in those who prefer to lock

\footnotetext{
${ }^{12}$ Answering at least two of the three CRT questions correctly.

${ }^{13}$ Segment groups 1 to 4 were classified as having positive environmental attitudes.
} 
Table 3 Group characteristics

\begin{tabular}{llllll}
\hline Group & $\mathrm{A}$ & $\mathrm{B}$ & $\mathrm{C}$ & $\mathrm{D}$ & Total \\
\hline Mean Age & 20.8 & 20.6 & 20.0 & 19.8 & 20.2 \\
Prop. Female & $60 \%$ & $44 \%$ & $50 \%$ & $56 \%$ & $52 \%$ \\
Home Own. & $80 \%$ & $70 \%$ & $83 \%$ & $84 \%$ & $£ 0 \%$ \\
Monthly Exp. & $£ 167.4$ & $£ 257.0$ & $£ 226.7$ & $£ 232.2$ & $£ 227.7$ \\
Valuation & 4.93 & 3.09 & 4.25 & 3.91 & 4.07 \\
CRT & 1.77 & 1.63 & 1.83 & 1.53 & 1.69 \\
\# Subjects & 31 & 27 & 30 & 32 & 120 \\
Percent & $26 \%$ & $22 \%$ & $25 \%$ & $27 \%$ & $100 \%$ \\
\hline
\end{tabular}

The Total column presents mean values for the full sample. A series of Pearson $\chi^{2}$-tests (categorical variables) and $t$-tests (continuous variables) assessing differences between the four groups in each of the characteristics found no statistically significant differences. The Valuation values were obtained from an intercept-only interval regression on the value brackets yielding mean willingness-to-pay estimates. The values obtained are considered to be comparable to the $£ 5$ conversion rate adopted for the control of the magnitude effect in the experiment, therefore confirming that the monetary and environmental tasks were perceived to be of an equivalent magnitude by subjects

in the amount they receive and not gamble at all (option 0). There is a drop in the probability of choosing the safer gamble (gamble 1) and a subsequent increase in the probability of choosing the two riskier gambles (gamble 3 and 4 ) is observed for both goods (money and environment). This suggests incentives may result in slightly riskier gambles being selected. However, this is not confirmed by $\chi^{2}$ and KS tests for statistical differences.

Table 5 presents the raw responses to the discounting task. For both goods, the frequency of high discount rates (switching points 5 and 6) drops once incentives are introduced. Again such effect, however, is not confirmed by $\chi^{2}$ and KS tests. ${ }^{14}$

\subsection{Estimation of risk aversion and time preference}

Table 6 presents regression results from structural models estimating risk (columns 2 and 3) and discounting (columns 4 and 5) parameters separately. In estimating discounting the common assumption of risk neutrality $(r=0)$ is imposed. For each case we first estimate a constant-only model and subsequently parameterize risk and

\footnotetext{
${ }^{14}$ While the risk aversion task only generated one observation, the discounting task generated 18 , which presented an opportunity to observe inconsistent responses. $81 \%$ subjects had one switching point in the discounting tasks and therefore exhibited no inconsistency. However, there were some instances where subjects alternated between smaller sooner and larger later choices in the payment ladder more than once. Seven subjects exhibited such behavior in more than one discounting task and are, hence, dropped from the dataset, as either unable to understand the task or wilfully uncooperative. This brings the number of observations to 113. In the remaining 16 instances of inconsistencies this double switching happened in only one of the 3 discounting tasks undertaken, and subjects were assumed to have made an error and the observations for this particular choice was amended. Sensitivity testing suggests results are robust to the exclusion of these 16 observations.
} 
Table 4 Risk aversion

\begin{tabular}{|c|c|c|c|c|}
\hline & \multicolumn{2}{|l|}{ Monetary risk } & \multicolumn{2}{|c|}{ Environmental risk } \\
\hline & $\begin{array}{l}\text { Hypothetical } \\
(\%)\end{array}$ & $\begin{array}{l}\text { Incentivised } \\
(\%)\end{array}$ & $\begin{array}{l}\text { Hypothetical } \\
(\%)\end{array}$ & $\begin{array}{l}\text { Incentivised } \\
(\%)\end{array}$ \\
\hline 0 & $16.7 \%$ & $22.6 \%$ & $25.0 \%$ & $25.9 \%$ \\
\hline 1 & $30.0 \%$ & $16.1 \%$ & $37.5 \%$ & $25.9 \%$ \\
\hline 2 & $33.3 \%$ & $32.3 \%$ & $9.4 \%$ & $11.1 \%$ \\
\hline 3 & $3.3 \%$ & $9.7 \%$ & $0.0 \%$ & $7.4 \%$ \\
\hline 4 & $16.7 \%$ & $19.4 \%$ & $28.1 \%$ & $29.6 \%$ \\
\hline Pearson $\chi^{2}$ & & 2.55 & & 3.04 \\
\hline$p$-value & & 0.64 & & 0.55 \\
\hline Kolmogorov-Smirnov $D$ & & 0.09 & & 0.11 \\
\hline p-value & & 0.99 & & 0.98 \\
\hline
\end{tabular}

The table presents the percentage of subjects who selected each of the 5 gambles in the monetary risk aversion test in the hypothetical (column 2) and incentivised (column 3) treatments and for the environmental risk aversion test in the hypothetical (column 4) and incentivised (column 5) treatments. The bottom panel displays the results obtained from the tests based on the null of no difference between the risk aversion choices made in the incentivised and in the hypothetical treatments

discounting parameters as per Eq. 10, leaving the respective noise parameters again as constants.

Our estimate of the risk parameter, 0.756, indicates moderate levels of risk aversion consistent with previous estimates by Andersen et al. (2008), while our estimate of the discounting parameter of $18 \%$ is within the wide range of acceptable values documented in Frederick et al. (2002). We find no evidence that any of our treatment variables (incentives or domain) have any impact on risk aversion parameter estimates. There is however, evidence for an effect of domain and incentives for those playing in the environmental arm of the experiment for discounting. Discount rates elicited range from $11.8 \%$ in the hypothetical monetary task, to $12.1 \%$ in the real monetary task, to $14.8 \%$ in the real environmental task and up to $22.2 \%$ in the hypothetical environmental task. However, we note that such estimates rely on risk neutrality, whereas our estimated risk aversion suggests respondents are, in fact, risk averse.

Table 7 presents results from the joint estimation of $r$ and $\delta$ using both exponential and hyperbolic functional forms for discounting. As previously, for each functional form, we, initially, estimate a constant-only model and subsequently add treatment interaction terms to both equations in turn. Note that in all models, noise parameters are included as constant only. A risk parameter of 0.77 is consistent with those in Table 6 above. The discounting parameter decreases, as expected, to $2.8 \%$ once the utility function is allowed to adopt the curvature provided by the risk aversion parameter. Both results are consistent with findings in Andersen et al. (2008). We find no evidence that incentives have any effect on either the risk or discounting 
Table 5 Discounting

\begin{tabular}{|c|c|c|c|c|}
\hline \multirow{2}{*}{$\begin{array}{l}\text { Switching } \\
\text { Point }\end{array}$} & \multicolumn{2}{|c|}{ Monetary discounting } & \multicolumn{2}{|c|}{ Environmental discounting } \\
\hline & $\begin{array}{l}\text { Hypothetical } \\
\text { (\%) }\end{array}$ & $\begin{array}{l}\text { Incentivised } \\
(\%)\end{array}$ & $\begin{array}{l}\text { Hypothetical } \\
(\%)\end{array}$ & $\begin{array}{l}\text { Incentivised } \\
(\%)\end{array}$ \\
\hline 0 & $8.1 \%$ & $15.5 \%$ & $12.1 \%$ & $17.4 \%$ \\
\hline 1 & $9.3 \%$ & $7.1 \%$ & $2.2 \%$ & $2.9 \%$ \\
\hline 2 & $11.6 \%$ & $10.7 \%$ & $2.2 \%$ & $5.8 \%$ \\
\hline 3 & $9.3 \%$ & $7.1 \%$ & $9.9 \%$ & $8.7 \%$ \\
\hline 4 & $7.0 \%$ & $13.1 \%$ & $13.2 \%$ & $14.5 \%$ \\
\hline 5 & $31.4 \%$ & $25.0 \%$ & $19.8 \%$ & $24.6 \%$ \\
\hline 6 & $23.3 \%$ & $21.4 \%$ & $40.1 \%$ & $26.1 \%$ \\
\hline Pearson $\chi^{2}$ & & 4.73 & & 5.16 \\
\hline$p$-value & & 0.58 & & 0.52 \\
\hline Kolmogorov-Smirnov $D$ & & 0.08 & & 0.15 \\
\hline$p$-value & & 0.90 & & 0.33 \\
\hline
\end{tabular}

The table lists the percentages of subjects who switched from the smaller sooner to the larger later in the monetary discounting task in the hypothetical and incentivised treatments (columns 2 and 3 respectively) and for the environmental discounting task in the hypothetical and incentivised treatments (columns 4 and 5 respectively). The bottom panel displays the results obtained from the tests based on the null of no difference between the discounting choices made in the incentivised and in the hypothetical treatments

choices made. However, we do find that the environmental domain impacts both risk and discounting estimates. The risk aversion parameter goes from 0.75 in the hypothetical monetary task ( 0.75 in the real monetary task) to 0.89 in the hypothetical environmental task ( 0.82 in the real environmental task) implying subjects are more risk averse when playing for plants than they are for money. The discount rate goes from $1.9 \%$ in the hypothetical monetary task (1.9\% in the real monetary task) to $3.5 \%$ in the hypothetical environmental task $(2.9 \%$ in the real environmental task) implying higher levels of discounting for goods in the environmental domain. The noise parameter for risk choices, $\mu$, is consistently larger than that for discounting choices, $v$, which Andersen et al. (2008) interpret as an indication of the cognitive difficulty of the task. Overall, results are largely consistent to different specifications of the functional form of the utility function as can be seen from the latter three columns displaying results for the hyperbolic specification.

We next move on to introduce and explore heterogeneity. Table 8 presents joint estimation results making parameters functions of treatments and four different socio-demographic variables $(X)$, namely sex, CRT, expenditure and environmental attitudes, as defined in Section 3.4. Each column uses a different socio-demographic variable $(X)$ to parametrize the risk (columns 2 to 5) and discounting (columns 6 to $9)$ equations. 
Table 6 Estimation results from structural models estimating risk and discounting parameters independently

\begin{tabular}{|c|c|c|c|c|}
\hline & Risk Aversion & & Discounting & \\
\hline \multicolumn{5}{|l|}{$r$} \\
\hline Real & & $\begin{array}{l}0.036 \\
(0.086)\end{array}$ & & \\
\hline Environment & & $\begin{array}{l}0.017 \\
(0.149)\end{array}$ & & \\
\hline Environment $\times$ Real & & $\begin{array}{l}-0.003 \\
(0.303)\end{array}$ & & \\
\hline Constant & $\begin{array}{l}0.756^{* * * *} \\
(0.059)\end{array}$ & $\begin{array}{l}0.738 * * * \\
(0.061)\end{array}$ & & \\
\hline$\mu$ & $\begin{array}{l}0.411 * * * \\
(0.072)\end{array}$ & $\begin{array}{l}0.409 * * * \\
(0.071)\end{array}$ & & \\
\hline$d$ & & & & \\
\hline Real & & & & $\begin{array}{l}0.001 \\
(0.012)\end{array}$ \\
\hline Environment & & & & $\begin{array}{l}0.104 * * * \\
(0.024)\end{array}$ \\
\hline Environment $\times$ Real & & & & $\begin{array}{l}-0.075^{* *} \\
(0.031)\end{array}$ \\
\hline Constant & & & $\begin{array}{l}0.180 * * * \\
(0.033)\end{array}$ & $\begin{array}{l}0.118 * * * \\
(0.007)\end{array}$ \\
\hline$v$ & & & $\begin{array}{l}0.055^{* * *} \\
(0.027)\end{array}$ & $\begin{array}{l}0.027 * * \\
(0.008)\end{array}$ \\
\hline Observations & 113 & 113 & 113 & 113 \\
\hline
\end{tabular}

This table presents the results obtained from ML estimations separately for the risk and discounting data. Columns 2 and 3 present estimates for the CRRA, $r$, equation. Columns 4 and 5 present estimates for the discount rate, $\delta$, equation assuming risk neutrality $(r=0) . \mu$ and $v$ are noise parameters for risk and discounting, respectively. Robust standard errors in parentheses; *** $\mathrm{p}<0.01$, ** $\mathrm{p}<0.05, * \mathrm{p}<0.1$

For risk aversion, we observe a consistent and statistically significant effect of domain, whereby those playing in the environmental domain have a higher risk aversion parameter. There is little heterogeneity in the effect of domain across sociodemographics with only exception that of the high expenditure dummy which albeit statistically signifiant is small in magnitude. There is no evidence of an effect or heterogeneity in the effect of incentives on risk aversion by sex and expenditure. However, some main or heterogeneous effects are observed for high CRT and environmental attitudes (i.e. Green) dummies. Specifically, controlling for high CRT in 
Table 7 Estimates of risk and discounting from joint structural models using exponential and hyperbolic functional forms for discounting

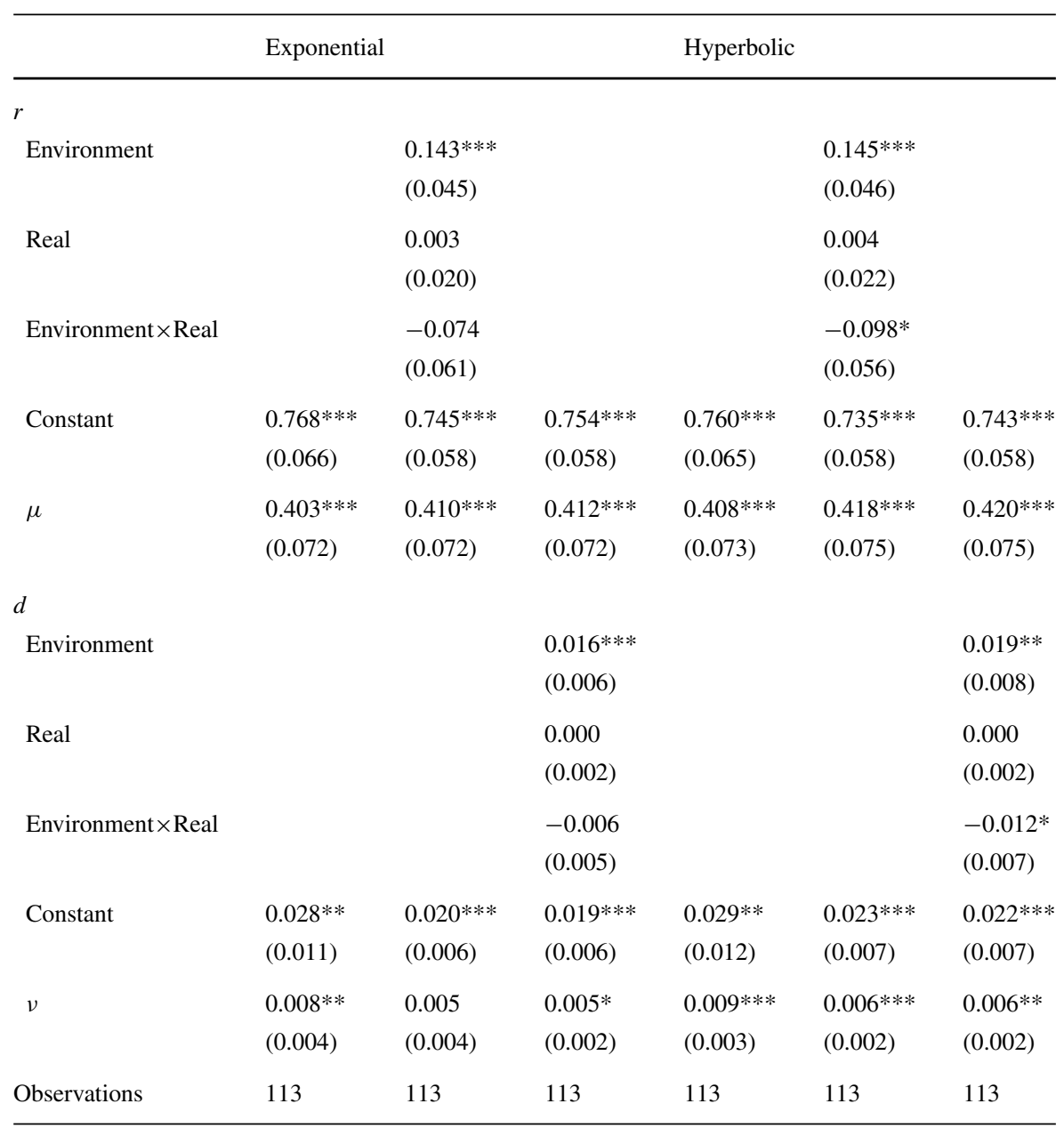

The table presents estimates from the joint estimation of risk and discounting equations. Column 2 presents results for $r$ and $\delta$ parameters along with their noise parameters. Column 3 parametrizes the $r$ equation and Column 4 parametrizes the $\delta$ equation with the two treatment variables and their interaction. The same pattern of results is repeated for Columns 5, 6 and 7 using a hyperbolic discounting specification. Robust standard errors in parentheses; *** $\mathrm{p}<0.01, * * \mathrm{p}<0.05, * \mathrm{p}<0.1$

the equation, we find that those in the incentivized environmental treatment have a statistically signifiant lower risk aversion parameter. Controlling for environmental attitudes and their interactions, among those without green attitudes playing with real incentives results in significantly higher risk aversion parameters both for money and environment, while among those with green attitudes incentives make no difference for money but decrease the risk aversion parameter for the environment domain. The rest of the estimable parameters (i.e. noise and discount) are similar across all four columns. 


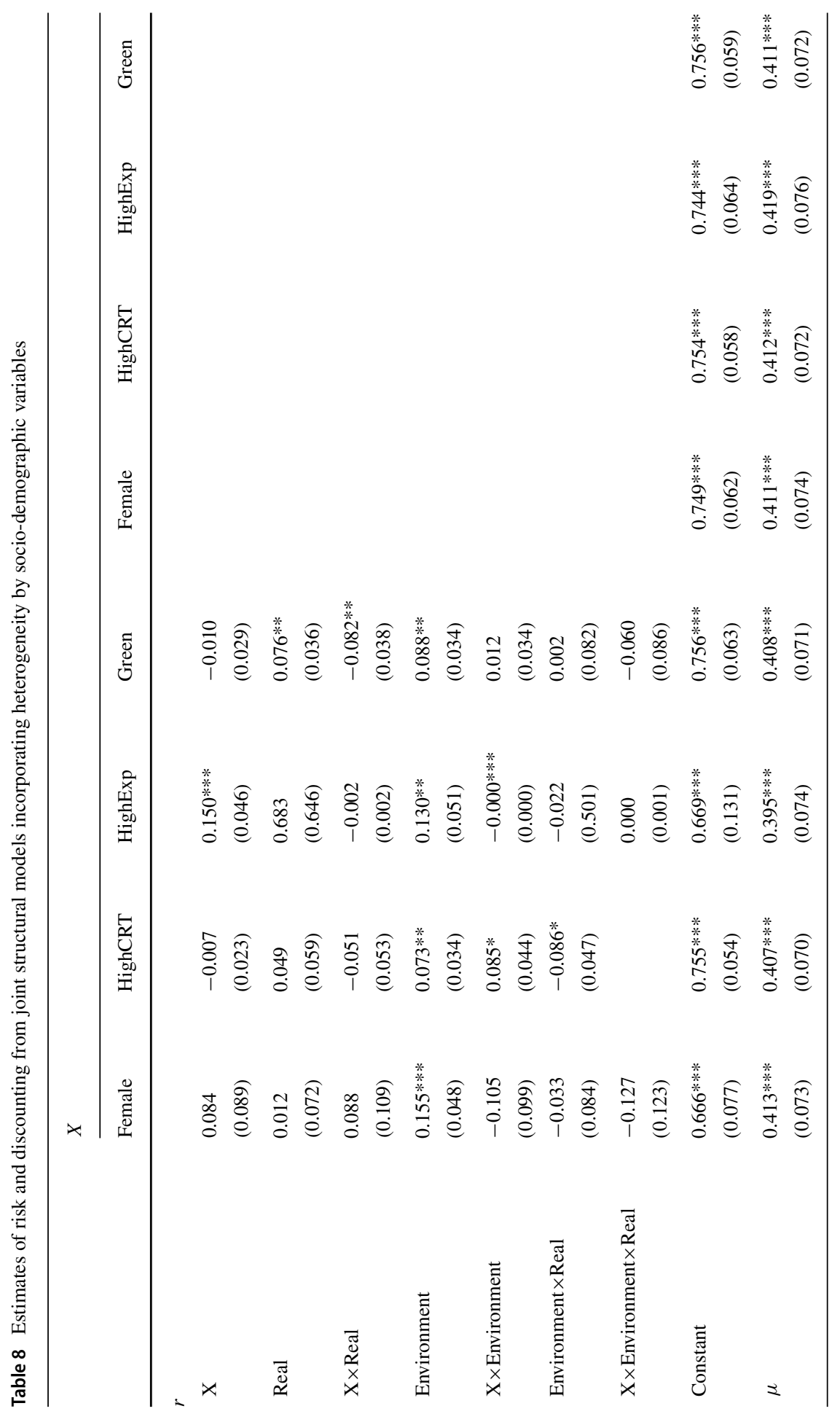




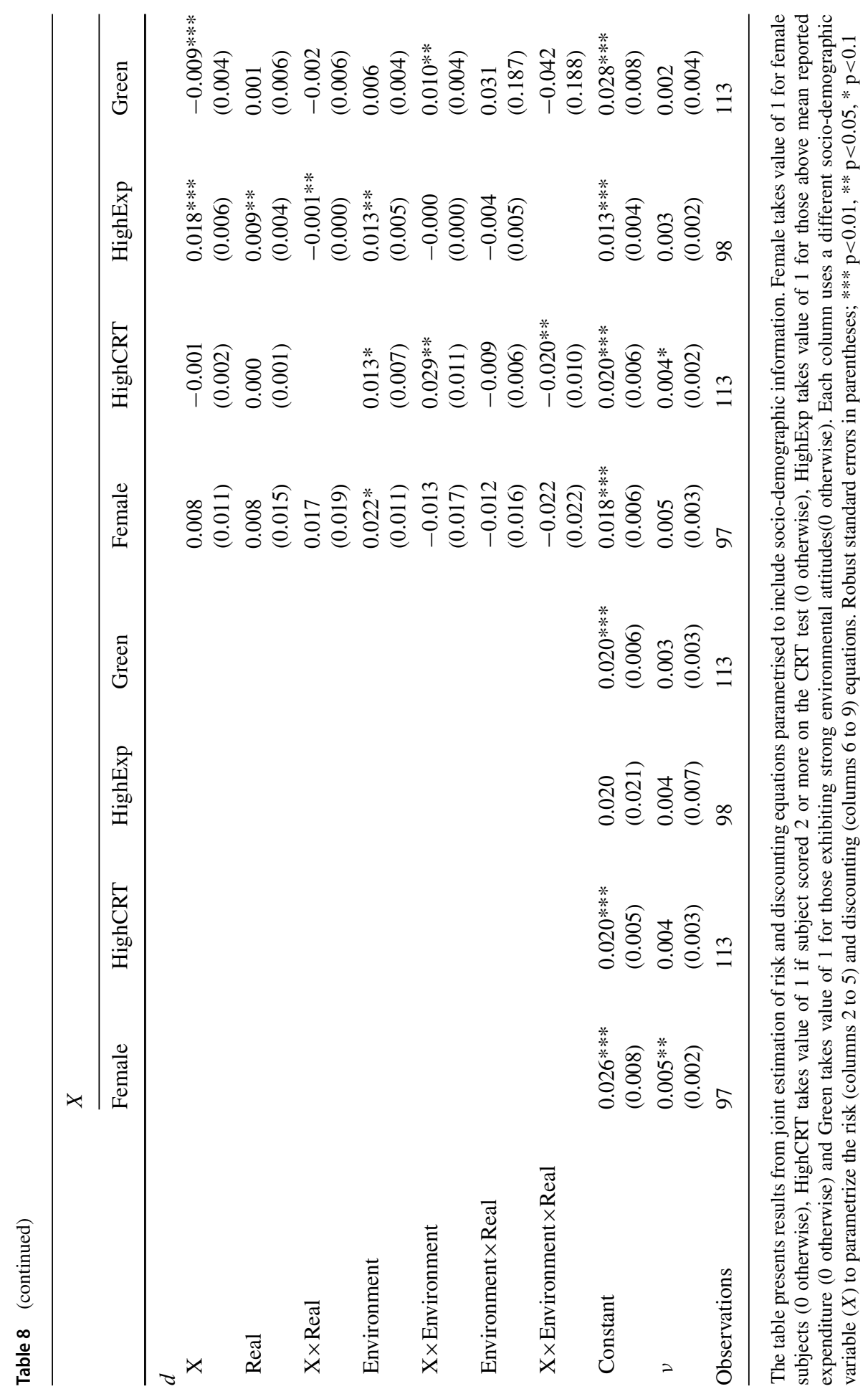


When looking at the discounting parameter, both expenditure and environmental attitudes emerge as significant main effects with the former resulting in an increase in the discount rate, suggesting that those with above median expenditure are less willing to wait for outcomes, while the latter (i.e. Green) decreases the discount rate implying that those with positive environmental attitudes are willing to delay an outcome with greater ease. Overall, across all four columns discount rates are higher for those in the environment domain, while values are even higher for those with high CRT and green environmental attitudes. Incentives have no effect in columns six and nine (i.e. introducing sex and green attitudes). Significantly lower discount rates are observed for those with high CRT playing for real in the environment domain. Controlling for expenditure levels, significantly higher discount rates are expressed for those playing for real in either domain with a small drop in the rate for those with above median expenditure. As previously, the remaining estimable parameters (i.e. risk aversion and noise) are largely similar across all columns.

\section{Discussion}

Incentives are considered to enhance saliency and encourage truthful elicitation of preferences and motivate sufficient cognitive effort. This study investigates, in an experimental setting, the impact of incentives on decisions in risk aversion and discounting tasks for both monetary and environmental goods.

A priori expectations are limited for risk aversion tasks, as economic intuition offers little guidance as to whether incentives would be expected to make subjects display increased or decreased risk aversion. For discounting tasks, a priori expectation could suggest that real payoffs would heighten the dis-utility of waiting and results in higher discount rates for incentivised treatments (Kirby \& Maraković, 1995; Coller \& Williams, 1999). Our evidence suggests that, on average, incentives have little effect on estimated parameters in either risk aversion or discounting tasks irrespective of the monetary or environmental domain. This confirms previous work such as Camerer and Hogarth (1999) who also found financial incentives in money tasks had no effect on mean values, as well as those from other non-strategic games (Mentzakis \& Mestelman, 2013) who also report no incentive effects.

However, our findings offer strong evidence of a domain effect with risk and discounting parameters both influenced by the nature of the environmental good, which contradicts the conclusions of Ioannou and Sadeh (2016) where no domain effect was found despite both studies using the same data for the incentivised treatment. Differences in findings are likely due to different econometric approaches adopted with the earlier paper opting for independent reduced form estimations for risk and discounting. This raises some pertinent questions on the lack of consistently strong evidence for a domain effect in discounting, suggesting that the omission of risk elicitation in discounting experiments might be yielding misleading results.

In addition, exploring treatment and socio-demographics heterogeneity some interesting patterns emerge for both risk aversion and discounting with higher levels of income and strong environmental attitudes both playing a role in influencing risk aversion and discounting parameters. For risk aversion, controlling for subjects' 
reflective thinking ability (i.e. CRT) results in incentivized environmental treatments exhibiting a statistically significant lower risk aversion parameter. Controlling for environmental attitudes and their interactions, we find that among those with low pro-environmental attitudes incentives result in significantly higher risk aversion parameters both for money and environment, while among those with high proenvironmental attitudes incentives make no difference for money but reduce the risk aversion parameter for the environment domain. This implies that pro-environmental attitudes influence the direction of the incentive effect on risk aversion for subjects and potentially suggests that increasing the salience of a domain (the environmental domain in this case) may cause subjects to exhibit lower risk aversion.

Looking at discounting, we find significantly lower environmental discount rates for those with high CRT in the incentivized treatments, suggesting an increased patience for environmental goods is related to higher reflective thinking. This supports the findings in Hardisty and Weber (2009) who find that higher levels of CRT are correlated with lower levels of discounting. Controlling for expenditure levels, significantly higher discount rates are observed in incentivized treatments in either domain with a small drop in the rate for those with above median expenditure. Due to sample size restrictions, elaborating on the magnitude of such effects is not advisable, however they emerge as variables of interest to be incorporated in future research.

In conclusion, we elicit levels of risk aversion $(\mathrm{r}=0.77)$ and discounting $(\delta=2.8 \%)$ consistent with past literature. On average, we find no effect of incentives but we do find evidence of hypothetical bias when controlling for certain socio-demographic characteristics and their interactions. On the contrary, we find strong evidence of a domain effect across all specifications. Overall, heterogeneity in findings should be treated with caution and require further investigation to understand the dynamics at play. Future research should aim to further explore the external validity of these tasks and replicate past findings with real incentives before assessing methodological aspects.

Acknowledgements The authors are grateful to Michael Vlassopoulos, Zacharias Maniadis and Glenn Harrison for their comments and input into the various stages of the paper. We are indebted to the Editor-inChief, Kip Viscusi and an anonymous referee for their detailed and helpful comments, which significantly improved the paper. The research was supported by research funds from the Economic and Social Research Council (ESRC) and the Strategic Research Development Fund (SRDF) of the University of Southampton. The usual disclaimer applies.

Open Access This article is licensed under a Creative Commons Attribution 4.0 International License, which permits use, sharing, adaptation, distribution and reproduction in any medium or format, as long as you give appropriate credit to the original author(s) and the source, provide a link to the Creative Commons licence, and indicate if changes were made. The images or other third party material in this article are included in the article's Creative Commons licence, unless indicated otherwise in a credit line to the material. If material is not included in the article's Creative Commons licence and your intended use is not permitted by statutory regulation or exceeds the permitted use, you will need to obtain permission directly from the copyright holder. To view a copy of this licence, visit http://creativecommons.org/licenses/by/4.0/.

\section{References}

Andersen, S., Harrison, G. W., Lau, M. I., \& Rutström, E. E. (2008). Eliciting risk and time preferences. Econometrica, 76(3), 583-618. 
Andersen, S., Harrison, G. W., Lau, M. I., \& Rutström, E. E. (2014). Discounting behavior: A reconsideration. European Economic Review, 71, 15-33.

Andreoni, J., \& Sprenger, C. (2012). Estimating time preferences from convex budgets. American Economic Review, 102(7), 3333-56.

Battalio, R. C., Kagel, J. H., \& Jiranyakul, K. (1990). Testing between alternative models of choice under uncertainty: Some initial results. Journal of Risk and Uncertainty, 3(1), 25-50.

Beattie, J., \& Loomes, G. (1997). The impact of incentives upon risky choice experiments. Journal of Risk and Uncertainty, 14(2), 155-168.

Binswanger, H. P. (1980). Attitudes toward risk: Experimental measurement in rural india. American Journal of Agricultural Economics, 62(3), 395-407.

Brown, A. L., \& Healy, P. J. (2018). Separated decisions. European Economic Review, 101, $20-34$.

Camerer, C. (1995). Individual decision making. Princeton, NJ: Princeton University Press.

Camerer, C. F., \& Hogarth, R. M. (1999). The effects of financial incentives in experiments: A review and capital-labor-production framework. Journal of Risk and Uncertainty, 19(1-3), 7-42.

Charness, G., Gneezy, U., \& Halladay, B. (2016). Experimental methods: Pay one or pay all. Journal of Economic Behavior and Organization, 131, 141-150.

Coller, M., \& Williams, M. B. (1999). Eliciting individual discount rates. Experimental Economics, 2(2), $107-27$.

Cox, J. C., Sadiraj, V., \& Schmidt, U. (2015). Paradoxes and mechanisms for choice under risk. Experimental Economics, 18(2), 215-250.

Cubitt, R. P., Starmer, C., \& Sugden, R. (1998). On the validity of the random lottery incentive system. Experimental Economics, 1(2), 115-131.

Cummings, R. G., Harrison, G. W., \& Rutström, E.E. (1995). Homegrown values and hypothetical surveys: Is the dichotomous choice approach incentive-compatible? The American Economic Review, 85(1), 260-266.

Davis, D., \& Holt, C. (1993). Experimental economics. Princeton, NJ: Princeton University Press.

Defra (2008). A framework for pro-environmental behaviours. Technical report, Department for Environment Food and Rural Affairs.

Eckel, C. C., \& Grossman, P. J. (2002). Sex differences and statistical stereotyping in attitudes toward financial risk. Evolution and Human Behavior, 23(4), 281-95.

Edwards, W. (1953). Probability-preferences in gambling. The American Journal of Psychology, 66(3), 349-64.

Fischbacher, U. (2007). z-tree: Zurich toolbox for ready-made economic experiments. Experimental Economics, 10(2), 171-8.

Fox, J. A., Shogren, J. F., Hayes, D. J., \& Kliebenstein, J.B. (1998). Cvm-x: Calibrating contingent values with experimental auction markets. American Journal of Agricultural Economics, 80(3), 455-465.

Frederick, S. (2005). Cognitive reflection and decision making. Journal of Economic perspectives pp. $25-42$.

Frederick, S., Loewenstein, G., \& O’Donoghue, T. (2002). Time discounting and time preference: A critical review. Journal of Economic Literature, 40(2), 351-401.

Fudenberg, D., \& Levine, D. K. (2006). A dual-self model of impulse control. American Economic Review, 96(5), 1449-1476.

Grether, D. M., \& Plott, C. R. (1979). Economic theory of choice and the preference reversal phenomenon. The American Economic Review, 69(4), 623-638.

Hardisty, D. J., Thompson, K. F., Krantz, D. H., \& Weber, E.U. (2013). How to measure time preferences: An experimental comparison of three methods. Judgment and Decision Making, 8(3), 236-49.

Hardisty, D. J., \& Weber, E. U. (2009). Discounting future green: Money versus the environment. Journal of Experimental Psychology: General, 138(3), 329-40.

Harrison, G. W., \& Lau, M. I. (2005). Is the evidence for hyperbolic discounting in humans just an experimental artefact? Behavioral and Brain Sciences, 28, 657-7.

Harrison, G. W., Lau, M. I., \& Williams, M.B. (2002). Estimating individual discount rates in denmark: A field experiment. The American Economic Review, 92(5), 1606-17.

Harrison, G. W., \& Rutström, E. E. (2008). Experimental evidence on the existence of hypothetical bias in value elicitation methods, Volume 1 of Handbook of experimental economics results, Chapter 81, pp. 752-767. Elsevier.

Hogarth, R. M., \& Einhorn, H. J. (1990). Venture theory: A model of decision weights. Management Science, 36(7), 780-803. 
Holt, C. A., \& Laury, S. K. (2002). Risk aversion and incentive effects. The American Economic Review, 92(5), 1644-55.

Ioannou, C. A., \& Sadeh, J. (2016). Time preferences and risk aversion: Tests on domain differences. Journal of Risk and Uncertainty, 53(1), 29-54.

Johannesson, M. (1997). Some further experimental results on hypothetical versus real willingness to pay. Applied Economics Letters, 4(8), 535-536.

Kirby, K. N., \& Maraković, N. N. (1995). Modeling myopic decisions: Evidence for hyperbolic delaydiscounting within subjects and amounts. Organizational Behavior and Human Decision Processes, 64(1), 22-30.

List, J. A., \& Gallet, C. A. (2001). What experimental protocol influence disparities between actual and hypothetical stated values? Environmental and Resource Economics, 20(3), 241-254.

List, J. A., \& Shogren, J. F. (1998). Calibration of the difference between actual and hypothetical valuations in a field experiment. Journal of Economic Behavior and Organization, 37(2), 193-205.

Mentzakis, E., \& Mestelman, S. (2013). Hypothetical bias in value orientations ring games. Economics Letters, 120(3), 562-565.

Meyer, A. (2013). Estimating discount factors for public and private goods and testing competing discounting hypotheses. Journal of Risk and Uncertainty, 46(2), 133-173.

Murphy, J. J., Allen, P. G., Stevens, T. H., \& Weatherhead, D. (2005). A meta-analysis of hypothetical bias in stated preference valuation. Environmental and Resource Economics, 3(3), 313-325.

ONS (2015). Family spending. Technical report, Office for National Statistics.

Read, D. (2005). Monetary incentives, what are they good for? Journal of Economic Methodology, 2(2), $265-276$.

Smith, V. K., \& Mansfield, C. (1998). Buying time: Real and hypothetical offers. Journal of Environmental Economics and Managementx, 36(3), 209-224.

Smith, V. L., \& Walker, J. M. (1993). Monetary rewards and decision cost in experimental economics. Economic Inquiry, 31(2), 245-261.

Viscusi, W. K., Huber, J., \& Bell, J. (2008). Estimating discount rates for environmental quality from utility-based choice experiments. Journal of risk and Uncertainty, 37(2-3), 199-220.

Publisher's note Springer Nature remains neutral with regard to jurisdictional claims in published maps and institutional affiliations. 